Nota Técnica:

\title{
Los materiales utilizados en la ejecución de la bóveda encamonada del Salón de Plenos del Senado de España
}

\author{
Technical Note: \\ Materials used to build the wooden vault over the Plenary Hall \\ in the Spanish Senate Buiding
}

R. Bustamante ${ }^{(*)}$, J. Monjo(*), M. I. Sánchez de Rojas ${ }^{(* *)}$

Recepción/Received: 26-VII-10

Aceptación/Accepted: 10-V-11

\section{RESUMEN}

En este artículo se analizan los materiales de la bóveda encamonada que cubre el Salón de Plenos del Senado de España (hacia 1814-1820). Se han determinado en particular las características físico-mecánicas del mortero de yeso aplicado sobre vigas, tablas y enlistonados de madera de pino, entomizados con fibra de esparto para asegurar la adherencia y conformar la superficie de la bóveda. Con los análisis de DRX, SEM e IR, se ha completado la caracterización del mortero que presenta adiciones de cerámica cocida.

Palabras clave: Pinus Silvestris, yeso artesanal, cerámica triturada, fibra de esparto.
SUMMARY

The constituent materials used to build the wooden vault over the Plenary Hall in the Spain's Senate Building (ca 1814-1820) are analyzed in this paper. Characteristics of gypsum mortar applied on pine beams, boards and blockboard, have been determined. The esparto (=needlegrass) fibre provides a framework for the gypsum mortar to ensure adhesion and forming the surface of the dome. Physical-mechanical properties of the burnt clay-lightened gypsum mortars were determined with laboratory tests, while the composition of these materials was found with $X R D, S E M$ and IR.

Keywords: Pinus Silvestris, hand-mixed gypsum mortar, crushed fired clay, esparto fibre.

\footnotetext{
(*) Universidad Politécnica de Madrid (Madrid, España).

(**) Instituto de Ciencias de la Construcción Eduardo Torroja de Madrid (IETcc-CSIC) (Madrid, España). 


\section{INTRODUCCIÓN Y OBJETIVOS}

Con la finalidad de determinar el estado actual de la bóveda encamonada del Salón de Plenos, se realizó una toma de datos que se dividió en tres fases. Una primera, para definir la geometría del intradós, en base a un escaneo 3D, que sirvió también para determinar las fisuras y la inclinación que presentaba hacia el lado sur. La segunda y tercera que se exponen a continuación consistieron en la realización de calas y catas para el conocimiento de los materiales componentes, y para la realización de los ensayos de laboratorio respectivamente (1).

\section{ANTECEDENTES Y CARACTERIZACIÓN CONSTRUCTIVA DE LA BÓVEDA}

El Palacio del Senado situado en la plaza de la Marina de Madrid fue en su origen el colegio-convento de doña María de Aragón, levantado a finales del siglo XVI (2). La autoría de la adaptación de la iglesia como Salón de Sesiones, para convertirla en sede de las Cortes que se trasladaron de Cádiz a Madrid, se atribuye al ingeniero Antonio Prat hacia 1814, pero también al arquitecto Isidro Velázquez a quien se le encargó en 1815, convertir el salón en Parroquia Ministerial del Palacio Real, obras iniciadas en 1817; en 1820 el mismo Velázquez la vuelve a transformar en Salón de Cortes, y en octubre de ese mismo año Prat reemplazó a Velázquez (3). Los trabajos realizados desde fines de 1939 y parte de 1940 se destinaron a corregir los desperfectos ocasionados por impacto de obuses de artillería durante la Guerra Civil, 19361939 (4). Posteriormente a 1973 data la rehabilitación de la cubierta del Salón de Plenos, en la que se eliminaron los pares y correas de la armadura de madera y se reemplazaron por la actual armadura metálica.

Según los tipos conocidos de bóvedas encamonadas, adinteladas y autoportantes, se puede determinar que la del Salón de Plenos es una bóveda compuesta, conformada por un plafón central rectangular adintelado, y por una semibóveda autoportante cortada por dos lunetos en el eje transversal y por otro luneto en el lado norte, en el eje longitudinal (Figura 1).

El plafón central rectangular está formado por tablas apoyadas a media madera en unas vigas $T$ invertidas 0 vigas con saledizos. Las tablas tienen un espesor de $4 \mathrm{~cm}$, pero también se han empleado costeros de $6 \mathrm{~cm}$ de grueso, todos entomizados para asegurar la adherencia del mortero de yeso. El plafón está suspendido de los tirantes de las desaparecidas cerchas de madera que se apoyan en los muros este y oeste, mediante unas bridas colgadas de unas vigas de sujeción. El espesor total del plafón es de $155 \mathrm{~mm}$, incluyendo la capa de yeso de regularización, el relleno de yeso entre tablas o costeros y el guarnecido del intradós.

Los camones forman la semibóveda escarzana (el arco corresponde a un ángulo de $\left.60^{\circ}\right)$. Están colocados de forma alternada por su canto (Figura 2) y unidos de diferente forma al plafón, pues en el tramo sur los camones se unen por debajo del mismo más o menos hasta la mitad y en el lado norte y en los laterales, mediante ensambles a media madera de las testas a la viga $\mathrm{T}$ de borde. Los extremos inferiores de los camones se fijan al encadenado perimetral de la bóveda mediante espigas y listones clavados, con inclinación radial de las testas hacia el encadenado en el caso de los lados norte y sur.

El guarnecido de yeso del intradós tiene un enlucido de $2 \mathrm{~mm}$ de escayola, y una tela adherida posteriormente, sobre la que se ha aplicado la pintura, y unas yeserías decorativas actuales (rosetones). Una moldura perimetral separa el plafón de la semibóveda y define las formas curvas de los extremos del plafón por el intradós (Figura 3).

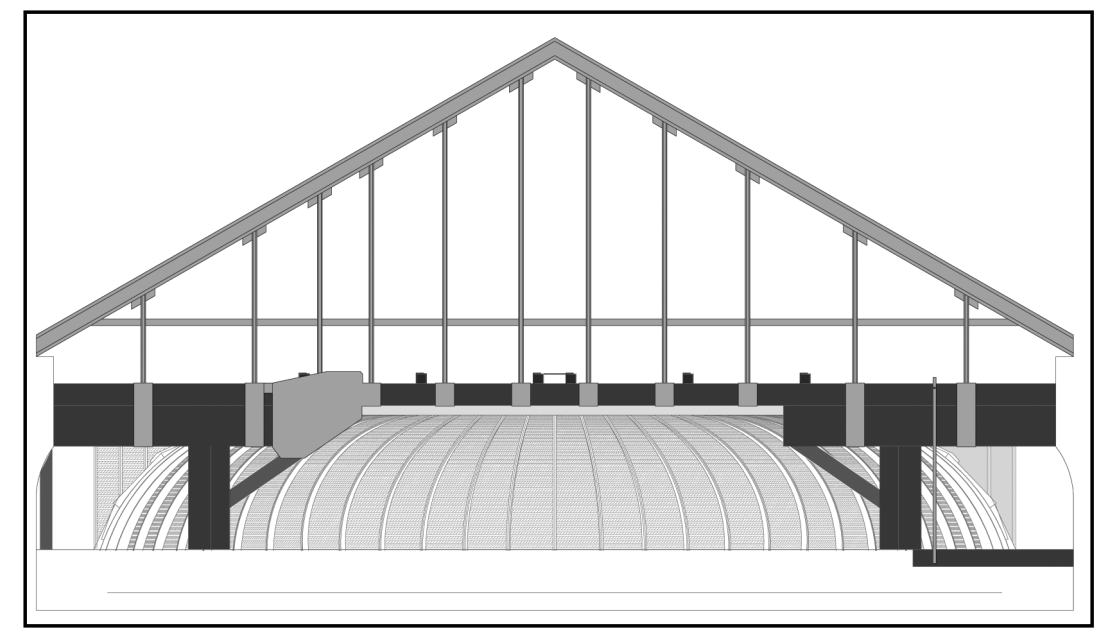

Figura 1. Alzado sur de la bóveda encamonada y de la cubierta. 


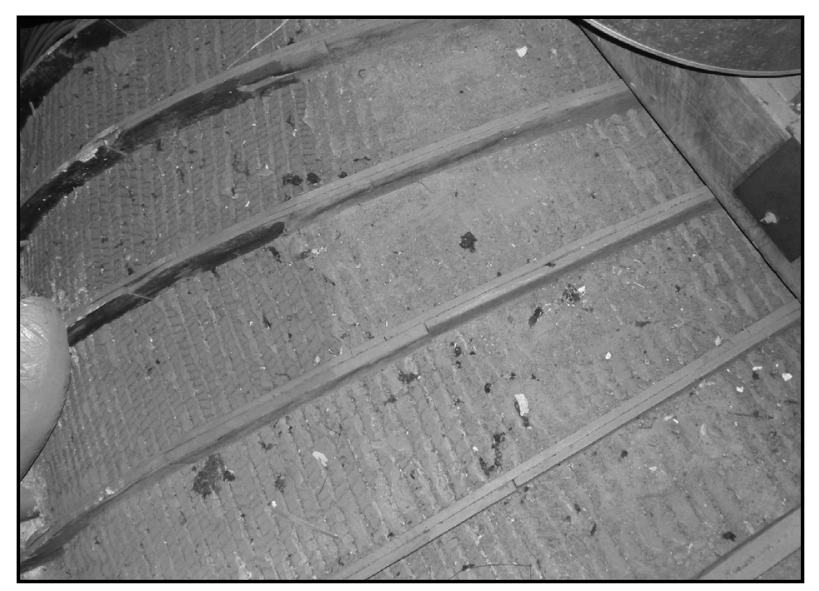

Figura 2. Camones y husos enlistonados (extradós lado sur).

\section{CARACTERIZACIÓN DE LOS MATERIALES}

A continuación se describe el procedimiento seguido para la toma de muestras de caracterización de los materiales y realización de los ensayos en laboratorio.

\subsection{Plan de toma de muestras}

Para caracterizar principalmente los morteros y pastas, se preparó un plan de toma de muestras. Se pretendía conocer los posibles cambios hechos en la bóveda, que no se habían registrado en la documentación escrita. Para ello se tomaron las medidas adecuadas para ingresar una plataforma con cesta y llegar a las partes altas del intradós. La bóveda tiene 27,35 m de largo por $16,55 \mathrm{~m}$ de ancho y 2,37 $\mathrm{m}$ de altura, desde la cornisa (intradós).

Todas las muestras cuentan con una ficha de toma de datos, características físicas (dimensiones, peso, color), resultados de laboratorio $(\mathrm{pH}$, porosidad abierta, densidad aparente, coeficiente de absorción, etc.), fotografías y observaciones en su caso (1).

\subsection{Ensayos físicos}

Para la caracterización de los morteros se aplicó la norma UNE-EN 998-2 "Especificaciones de los morteros para albañilería" (5).

Para la medición de la dureza superficial de los morteros y pastas, se aplicó la norma UNE UNE 102039; Yesos y escayolas de construcción. Determinación de la dureza Shore C y de la dureza Brinell (6).

En cuanto a la determinación de madera y fibras, se realizó la comparación por análisis microscópico con el apoyo de la base de datos de maderas del laboratorio del

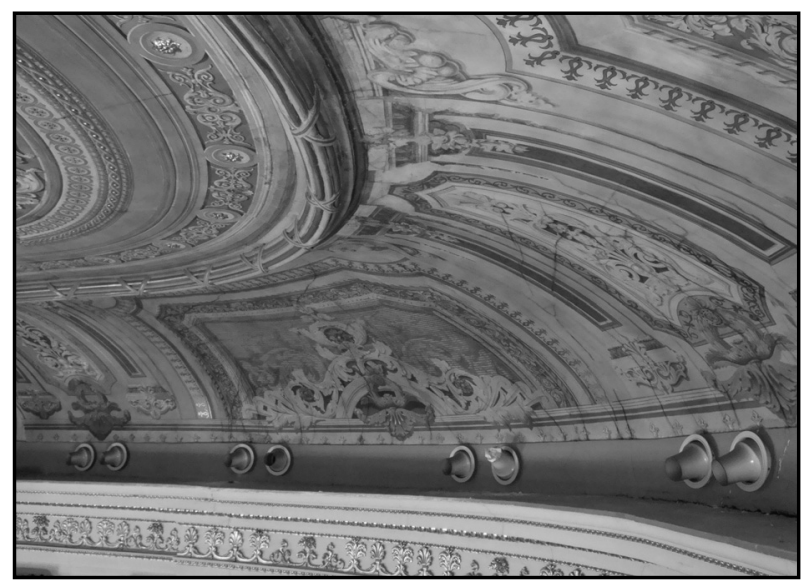

Figura 3. Plafón central con moldura perimetral de separación de la semibóveda y salidas de los conductos de climatización encima de la cornisa (intradós).

Departamento de Construcción de la ETS de Arquitectura, de la UPM.

La velocidad de los ultrasonidos se midió con un equipo calibrado Tico, operando a 0,5 kV. El Módulo de Young $E$, se calculó utilizando la fórmula bien conocida $E=\rho . v^{2}$, siendo $\rho$ la densidad normal de cada probeta $\left(\mathrm{kg} / \mathrm{m}^{3}\right)$ y $\mathrm{v}$, la velocidad de los ultrasonidos en condiciones de laboratorio $(\mathrm{m} / \mathrm{s})$.

\subsection{Determinación de la fracción fina/ fracción gruesa}

Se ha aplicado el método tradicional que consiste en tomar una porción de muestra, para disgregar cuidadosamente el árido de la parte cementante en un mortero cerámico y con un tapón de goma. A continuación se pasa por un tamiz de 0,088 $\mathrm{mm}$. Se pesa con precisión cada una de las fracciones. La parte fina (inferior a $90 \mathrm{~mm}$ ) se pone en un tubo de ensayo (para ser analizada) y la parte gruesa se machaca y se muele con el mortero de ágata, hasta obtener un polvo fino, que se introduce en otro tubo de ensayo para su análisis.

\subsection{Análisis DRX, SEM e IR}

En el apartado 5 se desarrollan los resultados de los análisis de difracción de rayos X (DRX), microscopía electrónica de barrido (SEM) y de microscopía infrarroja (IR).

\section{LOS MATERIALES CONSTITUYENTES}

A continuación se indican los resultados de la caracterización de los materiales de la bóveda encamonada. 


\subsection{La madera de los camones}

Usualmente en España se usa el Pinus Silvestris en la edificación, y para verificar las diferencias en las semibóvedas se analizaron dos muestras de madera que corresponden a un camón del lado norte (Figura 4) y a otro del lado sur (Figura 5). La primera procede de una conífera de crecimiento medio tipo Pinus Silvestris (pino de Valsaín), mientras que la segunda es una conífera de crecimiento lento, en función de la anchura de los anillos de verano e invierno, tipo pino de Oregón o Douglas-fir o Pseudotsuga menziesii, ambas maderas blandas. Esta diferencia confirmaría que la ejecución de la semibóveda sur corresponde a una etapa diferente, intervención en la que se eliminaría el luneto del cual se tiene constancia en la documentación histórica, y porque los acabados de los husos son diferentes a los de la semibóveda sur.

\subsection{Clavos y bridas}

Los materiales férricos usados en las uniones son clavos de hierro forjado, siendo los más pequeños de $10 \mathrm{~cm}$

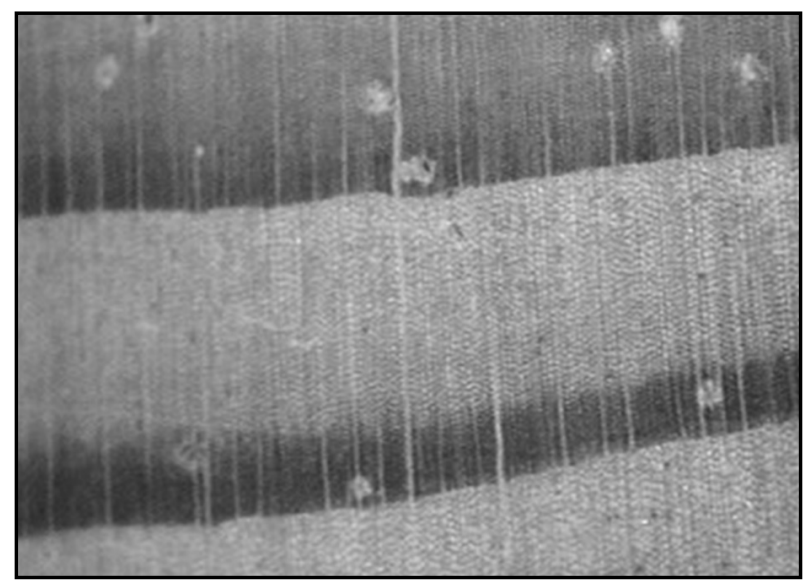

Figura 4. Tipo Pinus Silvestris.

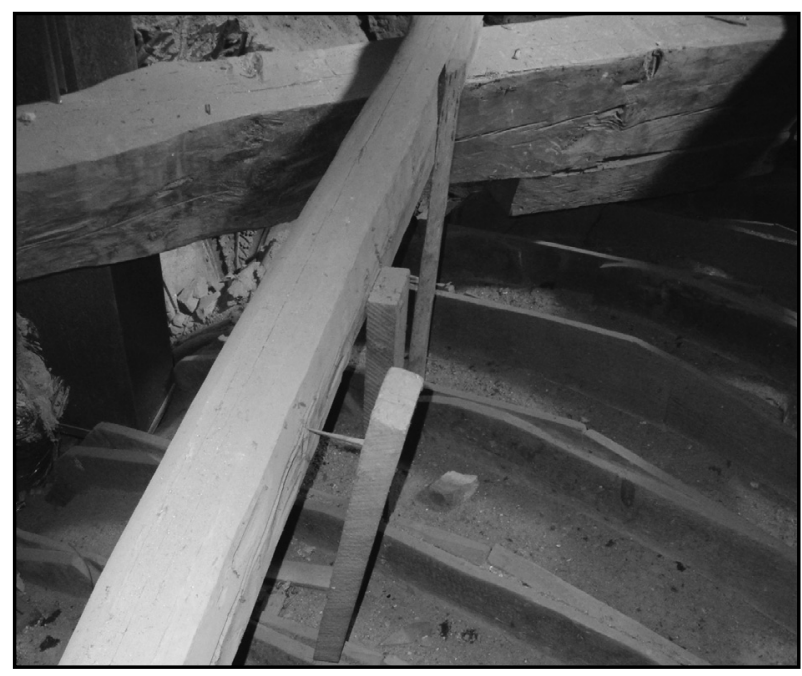

Figura 6 . Uniones a viga puente mediante piezas clavadas. de largo, con cabeza de $3 \mathrm{~mm}$ de sección y 13,76 mm de lado, y cuerpo de 5,5 mm x 5,2 mm, de sección rectangular en la parte superior, terminando en el extremo inferior en una base de $2 \mathrm{~mm}$ de lado (Figura 6). Por su parte, las bridas tienen $3 \mathrm{~cm}$ de ancho y $2 \mathrm{~mm}$ de espesor, de longitudes variables, y las uniones se han hecho por solape y clavado a la viga puente de sujeción o pieza de madera en su caso (Figura 7).

\subsection{Fibras de esparto}

Para conseguir la adherencia del mortero de yeso a la madera, las tablas del plafón y el enlistonado de la semibóveda están envueltos con cuerdas de esparto (gramínea Stipa tenacissima) denominada "tomiza", armando el conglomerado de yeso, de tal manera que se consigue que la fibra trabaje a tracción evitando el descuelgue de la masa en caso de rotura. El espesor medio de la tomiza es de $5 \mathrm{~mm}$ y su densidad aparente es de 0,37 g/ $\mathrm{cm}^{3}$. Existen dos tipos de "entomizado" (envolver la pieza de madera con tomiza):

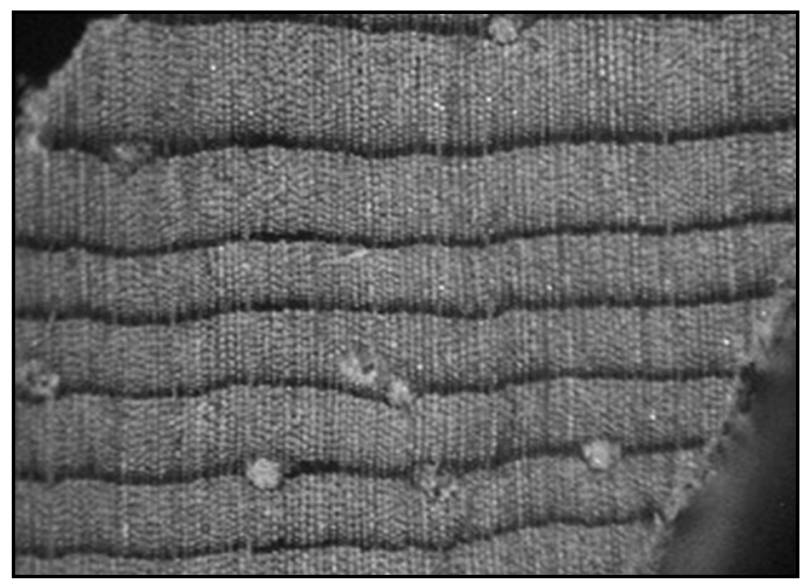

Figura 5. Iipo pino de Oregón o Douglas-fir, x 50.

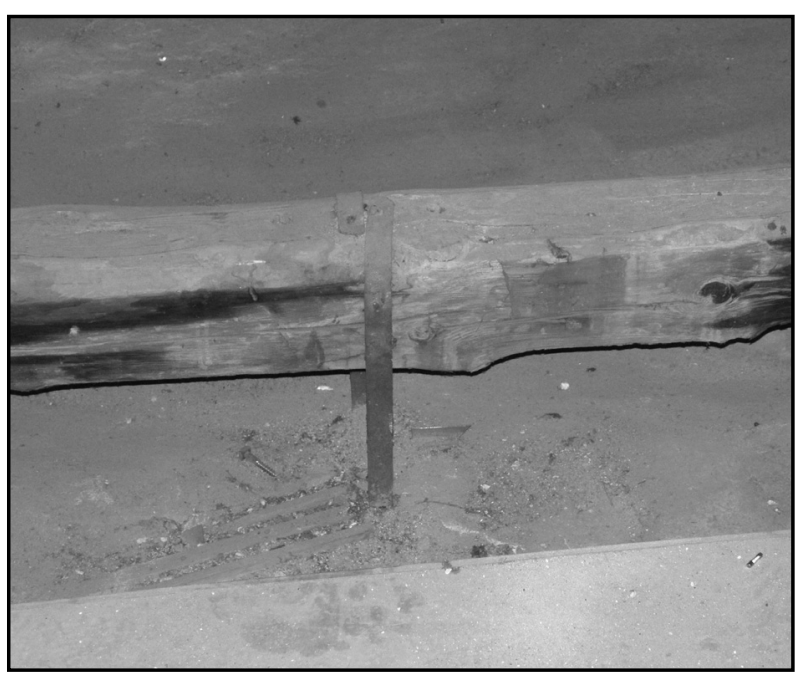

Figura 7. Brida de viga de sujeción del plafón. 


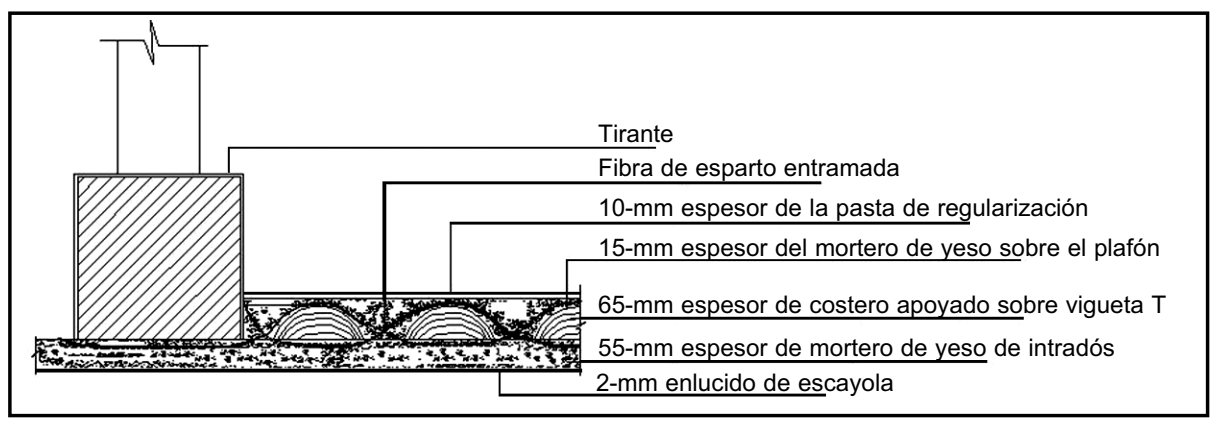

Figura 8. Entomizado por entramado.

- Por enrollado: aplicado individualmente a las vigas T y canecillos de las cornisas, enlistonados de los husos (superficies entre camones) y de otras superficies guarnecidas. El enrollado es perpendicular al elemento. En los extremos de los canes de la platabanda de la cornisa, la cuerda está aplicada de forma tupida, mientras que en los enlistonados se hilvana la fibra de forma inclinada y espaciada para cubrir más superficie con menos cantidad.

- Por entramado: las fibras pasan por encima y por debajo de las tablas que forman el plafón, de tal manera que las cuerdas se van cruzando en los espacios o entrevigado, como si fuera un tejido en el que las viguetas hacen de urdimbre (Figura 8).

\subsection{Morteros y pastas de yeso aplicados}

Analizadas las muestras obtenidas, se ha determinado que se han aplicado en la bóveda tres tipos de morteros: M.1-A, M.25 igual a M.18 y M.30, y M.24, y una pasta de yeso (M.25-C) cuya caracterización se resume en la Tabla 1.

\subsubsection{Morteros de yeso de granulometría gruesa del extradós}

Este mortero se ha aplicado sobre el plafón rellenando el entrevigado que previamente se había entramado con el cruce de fibras de esparto. Su espesor es variable, de 1,5 a $2 \mathrm{~cm}$ sobre los costeros, y de 3,5 a $4 \mathrm{~cm}$ sobre las tablas que tienen menos canto (muestra M.25).

Está formado por yeso artesanal de color beige con adiciones de granos grandes e irregulares. Presenta fragmentos de espejuelo (hasta de $40 \mathrm{~mm}$ por $15 \mathrm{~mm}$ ), arena, cerámica cocida machacada en granos de $5 \mathrm{~mm}$ y trozos más grandes, cenizas y fibras (Figura 9). La muestra M.18 tiene granos de cerámica cocida de $10 \mathrm{~mm}$, y el más grande es de $34,70 \mathrm{~mm} \times 38 \mathrm{~mm}$, también un grano de carbón de $4 \mathrm{~mm}$. La densidad aparente media es de $1,37 \mathrm{~g} / \mathrm{cm}^{3}$, porosidad abierta de $28,25 \%$, coeficiente de absorción 20,65\%, dureza Shore C de 67 unidades y $\mathrm{pH} 8$.

\subsubsection{Mortero de yeso de granulometría menos gruesa del intradós}

Se denomina así al mortero de granulometría de 6 a 8 $\mathrm{mm}$, aplicado en el intradós del plafón, con presencia de arena, cerámica machacada en granos finos, cenizas, fibras y nódulos de cal. Su densidad es de 1,35 g/ $\mathrm{cm}^{3}$, porosidad abierta de $27,05 \%$, coeficiente de absorción de $20 \%$, y dureza superficial de 38 unidades Shore C (M.1-A, Figura 10).

Tabla 1

Resumen comparativo de las muestras.

\begin{tabular}{|c|c|c|c|c|c|c|c|c|}
\hline Muestra & Situación del mortero & \begin{tabular}{|c|} 
Relación \\
fracción fina \\
/ fracción \\
gruesa (en \\
peso)
\end{tabular} & $\begin{array}{c}\text { Densidad } \gamma \\
\left(\mathbf{g} / \mathrm{cm}^{3}\right)\end{array}$ & $\begin{array}{c}\text { Porosidad } \\
\text { abierta \% }\end{array}$ & $\mathrm{C}_{\mathrm{a}} \%$ & $\begin{array}{c}\text { Shore C } \\
\text { hardness } \\
\text { Units/(N) } \\
\left(^{*}\right)\end{array}$ & $\begin{array}{l}\text { Ultrasonido } \\
\mathrm{m} / \mathrm{s}\end{array}$ & $\mathrm{E}(\mathrm{GPa})$ \\
\hline M.1-A & Mortero sobre plafón / intradós & $0.9 / 1$ & 1.35 & 27.05 & 20.00 & $38(16.91)$ & 1.890 & $3.572 .10^{-3}$ \\
\hline M.18 & Mortero de entrevigado de plafón / extradós N & - & 1.24 & 23.67 & 19.03 & $40(17.80)$ & - & - \\
\hline M.24 & $\begin{array}{c}\text { Mortero sobre enlistonado en intradós } \\
\text { de semibóveda }\end{array}$ & $2.5 / 1$ & 1.24 & 34.51 & 27.92 & $50(22.25)$ & - & - \\
\hline M.25 & Mortero de entrevigado de plafón / extradós centro & $1.2 / 1$ & 1.37 & 28.16 & 20.65 & $67(29.81)$ & - & - \\
\hline M.25-C & Pasta de yeso de nivelación de extradós & - & 1.15 & 42.05 & 34.50 & $35(15.57)$ & - & - \\
\hline M.30 & Mortero en antigua escalera & - & 1.33 & 28.25 & 21.18 & $58(25.81)$ & 1.957 & $5.09 .10^{-3}$ \\
\hline
\end{tabular}

(*) 100 Unidades Shore $=44.5 \mathrm{~N}$. 


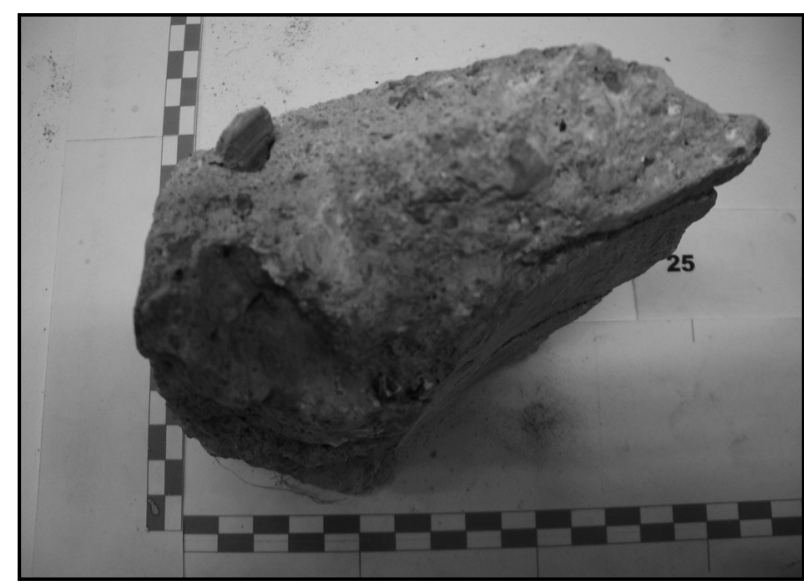

Figura 9. Espejuelo no calcinado y cerámica cocida en la masa de yeso (muestra M.25 de extradós).

Se diferencia del mortero 24 aplicado en la semibóveda del lado sur, en que este tiene menor densidad, $1,24 \mathrm{~g} / \mathrm{cm}^{3}$, su porosidad abierta es de $34,51 \%$, el coeficiente de absorción es más alto, aproximadamente $28 \%$, y en particular, en que la proporción de fracción fina de 2,5 respecto a 1 de fracción gruesa, establece una diferencia respecto a los morteros M.1-A y M-25. Aparentemente este mortero de yeso procedería de una actuación diferente, aunque también presenta cerámica en su composición.

El espesor del mortero M.1-A es de $50 \mathrm{~mm}$ a $55 \mathrm{~mm}$ y tiene un enlucido de $2 \mathrm{~mm}$ de escayola. El análisis por DRX no ofrece diferencias respecto al análisis del mortero del extradós, lo cual indica que se trataría de una sola intervención, como se expone a continuación.

En la medición por ultrasonidos, el resultado fue $1.890 \mathrm{~m} / \mathrm{s}$ para el mortero M.1-A, mientras que para la muestra 30 fue de $1,957 \mathrm{~m} / \mathrm{s}$, que procede de una antigua escalera situada en la cabecera del Salón, similar al M.25 y aportan datos de referencia para morteros de estas características.

Por otro lado, comparando los resultados del análisis físico con los morteros encontrados en enlucidos de edificaciones más antiguas (7), estos morteros de yeso son ligeros por su densidad aparente y alto coeficiente de absorción de agua, alrededor de $20 \%$, en los cuales ha influido la adición de cerámica triturada.

\subsubsection{Pasta de yeso de regularización del extradós}

Sobre el mortero del plafón del extradós se ha aplicado una pasta de yeso de 7,54 $\mathrm{mm}$ a 9,40 $\mathrm{mm}$ de espesor, para nivelar la superficie. Es un yeso moreno, densidad de $1,15 \mathrm{~g} / \mathrm{cm}^{3}$, porosidad abierta de $42,05 \%$, coeficiente de absorción de $34,50 \%$, pH 8 y dureza superficial de 35 unidades Shore C (M.25-C). En el tamizado de la muestra el tamaño máximo es de $2 \mathrm{~mm}$.

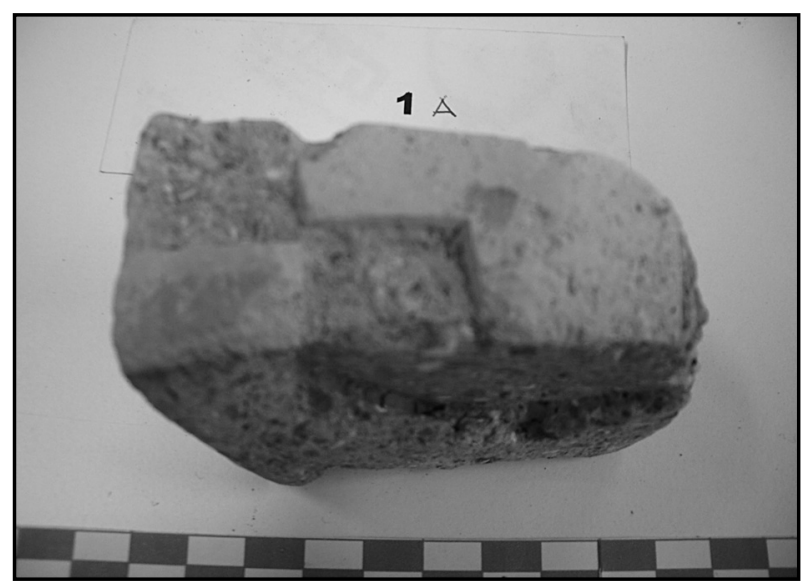

Figura 10. Muestra M.1-A en la que se aprecia la sección del mortero del intradós y el enlucido en la parte superior.

\subsubsection{Enlucido de escayola debajo de la tela}

El acabado del intradós del plafón tiene un enlucido de escayola de $2 \mathrm{~mm}$ aplicado sobre el mortero de yeso M.1-A. Su densidad aparente es de $1,04 \mathrm{~g} / \mathrm{cm}^{3}$. Presentaba una capa de pintura verde. Sobre este enlucido se ha aplicado la tela con pintura decorativa. Se pueden apreciar las fibras en los bordes de la cala efectuada y la sección del mortero del intradós (Figura 11).

\subsubsection{La decoración pictórica sobre tela}

Con respecto al acabado pictórico actual, no hemos conseguido datos históricos concretos sobre el momento de su ejecución, aunque por su aspecto se trataría de un marouflée, es decir, una tela pintada y pegada posteriormente sobre el techo. Suele ser corriente en la segunda mitad del XIX o principios del XX. Tratándose de bandas con motivos repetitivos, podría pensarse en la aplicación de telas previamente pintadas y unidas con solapes y clavos de sujeción (Figura 12). Las fisuras del guarnecido de yeso de viguerías y enlistonados han producido arrugas en la tela aunque no se aprecian rasgados.

En cualquier caso la conservación de los materiales orgánicos que presenta la bóveda implica el mantenimiento adecuado de la temperatura y humedad relativa para asegurar su conservación idónea (8).

\section{RESULTADOS DE LOS ANÁLISIS DE DRX, SEM E IR}

\subsection{Difracción de rayos $X(D R X)$}

Los análisis se llevaron a cabo con un difractómetro de rayos X D8 ADVANCE, fabricado por Bruker. En los difratogramas obtenidos (Figuras 13, 14, 15 y 16), se deduce que las muestras M-1 A y M-25 están formadas principalmente por: 


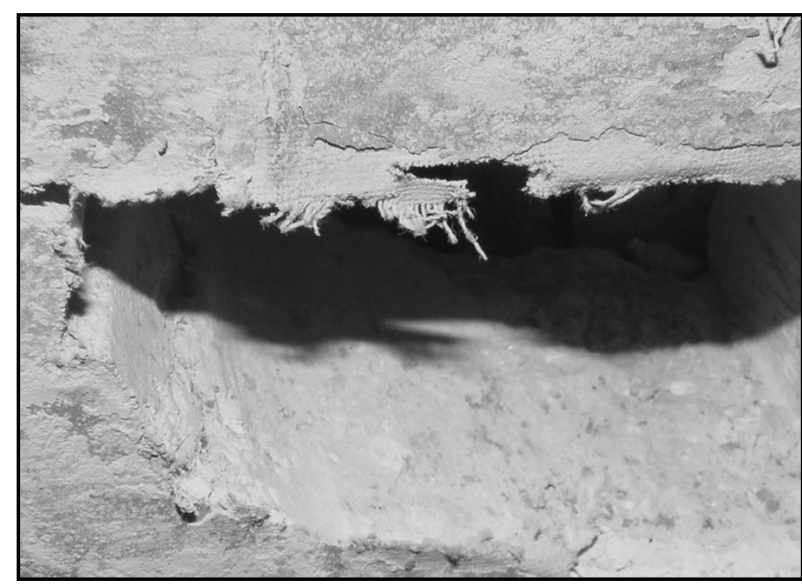

Figura 11. Sección del intradós del plafón de la bóveda cubierta por la tela pintada (fotografía tomada después de haber realizado la cata).

- Yeso (Y).

- Moscovita (M).

- Cuarzo (Q).

En la muestra M-25, a simple vista como se ha indicado, se observan partículas de arcilla cocida, ya que posiblemente se utilizó este material como árido. Sin embargo, debido a que el material cerámico tiene poca dureza, es previsible que se detecte también en la fracción más fina, ya que parte del árido ha pasado a esta fracción.

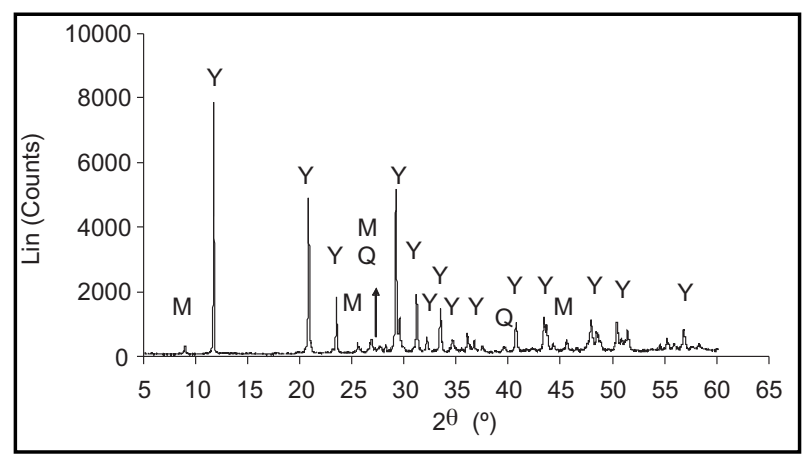

Figura 13. DRX de muestra M.1-A: fracción gruesa.

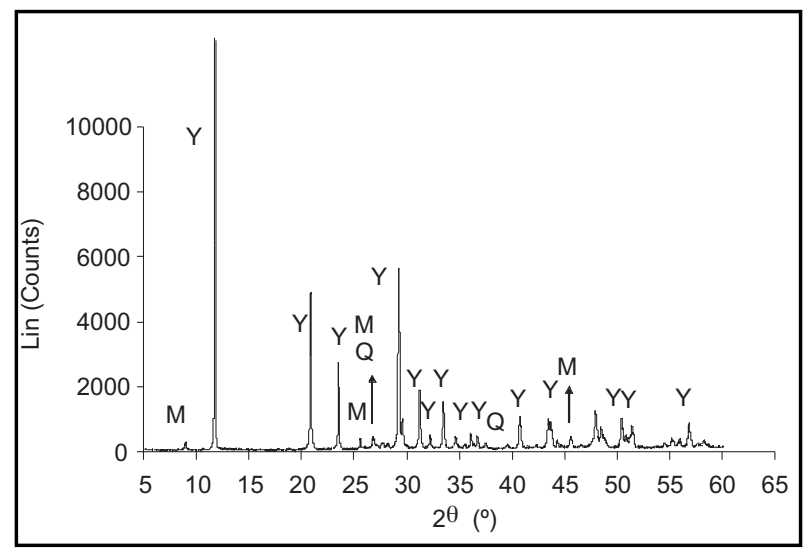

Figura 15. DRX de muestra M.25: fracción gruesa.

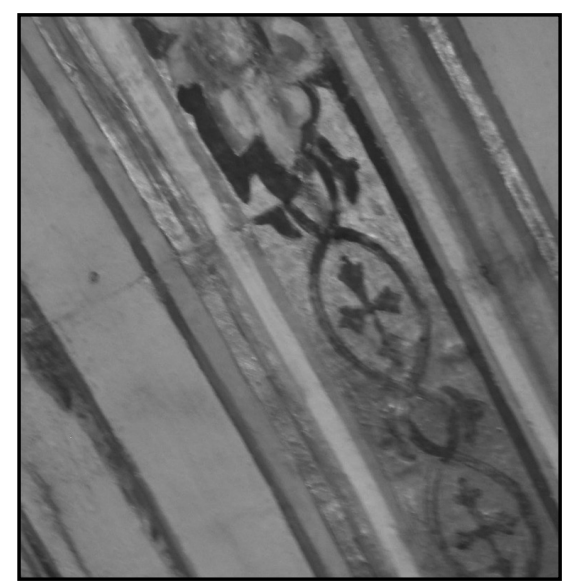

Figura 12. Banda decorativa clavada.

En la composición de los materiales procedentes de arcillas cocidas se encuentran: moscovita y cuarzo como compuestos cristalinos mayoritarios (9), por lo que se explica la presencia de estos compuestos cristalinos en los difractogramas obtenidos.

\subsection{Microscopía electrónica de barrido (SEM)}

En la muestra M.25 se ha llevado a cabo un estudio mediante microscopía electrónica de barrido (SEM) y el

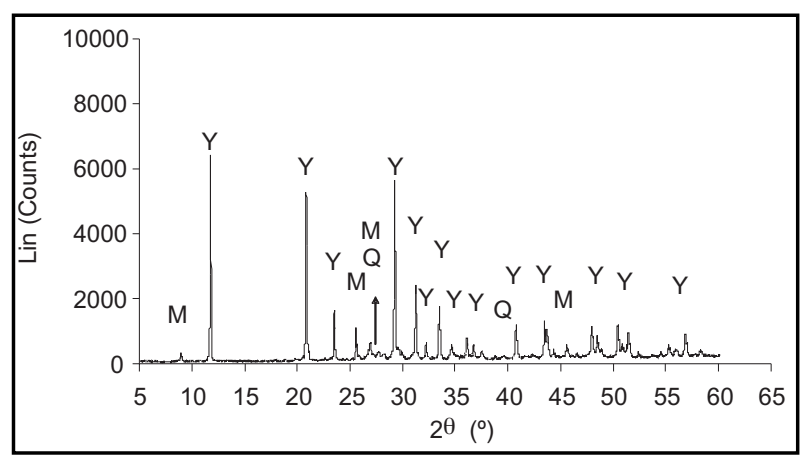

Figura 14. DRX de muestra M.1-A: fracción fina.

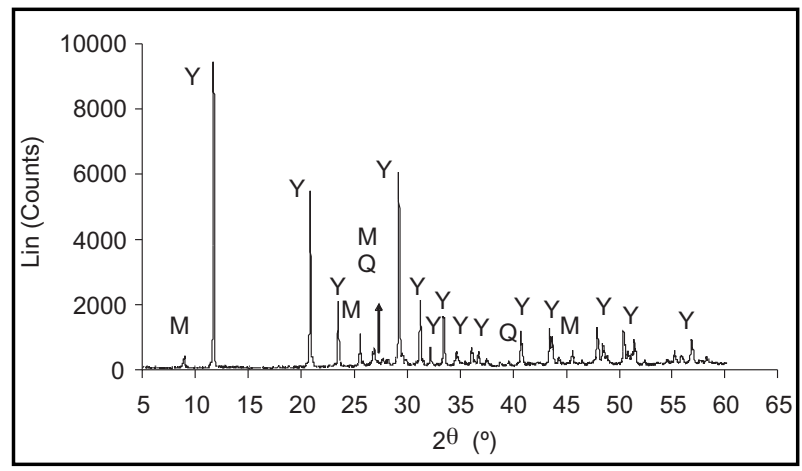

Figura 16. DRX de muestra M.25: fracción fina. 
microanálisis por energía dispersiva de rayos $\mathrm{X}$ (EDX), Figuras 17 y 18 que evidencia la presencia de material arcilloso.

El análisis se ha realizado con un equipo Philips modelo XL-30 con fuente de wolframio, con analizador EDX. Las muestras se fijan al portamuestras metálico mediante una lámina biadhesiva de grafito; posteriormente, la superficie se metaliza con oro para garantizar su conductividad.

Se ha verificado también la presencia de calcita en los morteros de intradós y extradós. Las proporciones son: yeso, $98,97+-2,76$ y calcita, $1,53+-0,65$. No se puede asegurar que proceda de una adición a la mezcla o que formaba parte de la materia prima, aunque se conoce de la existencia de morteros de cal y yeso en bóvedas encamonadas (10).

\subsection{Estudio realizado mediante microscopía IR}

También, en la muestra M.1C, que corresponde al relleno del plafón de la bóveda encamonada (extradós), se realizó un estudio de la capa superficial mediante espectroscopía de absorción infrarroja por transformada de Fourier (FTIR), utilizando un equipo NICOLETE 6700, fabricado por Thermo Fischer Scientific.
La presencia de yeso se pone de manifiesto con las bandas a 3550, 3405, 3245, 1680, 1620, 1144, 1120, 1003, 669 y $602 \mathrm{~cm}^{-1}$ (Figura 19).

\section{CONCLUSIONES}

Los morteros aplicados en la bóveda encamonada del Salón de Plenos son de yeso fabricado artesanalmente, con arena, cenizas, fibras, calcita en pequeña proporción, y adición de cerámica triturada, como así se demuestra por la presencia de moscovita y cuarzo como compuestos cristalinos mayoritarios que proceden de arcillas cocidas.

La presencia de la cerámica triturada que los yeseros usaron como árido, ha ayudado a aligerar el mortero $\left(1,35 \mathrm{~g} / \mathrm{cm}^{3}\right.$ a $\left.1,37 \mathrm{~g} / \mathrm{cm}^{3}\right)$. Teniendo en cuenta que es un yeso calcinado en hornos artesanales y molido manualmente, la materia prima no calcinada (espejuelo) se ha convertido en agregado grueso del mortero.

Los morteros aplicados en el intradós y en el extradós del plafón presentan similares características, con diferencias en el tamaño de los granos, más grandes en el extradós. Procederían de una misma actuación (primer cuarto del siglo XIX), no así el mortero aplicado en la

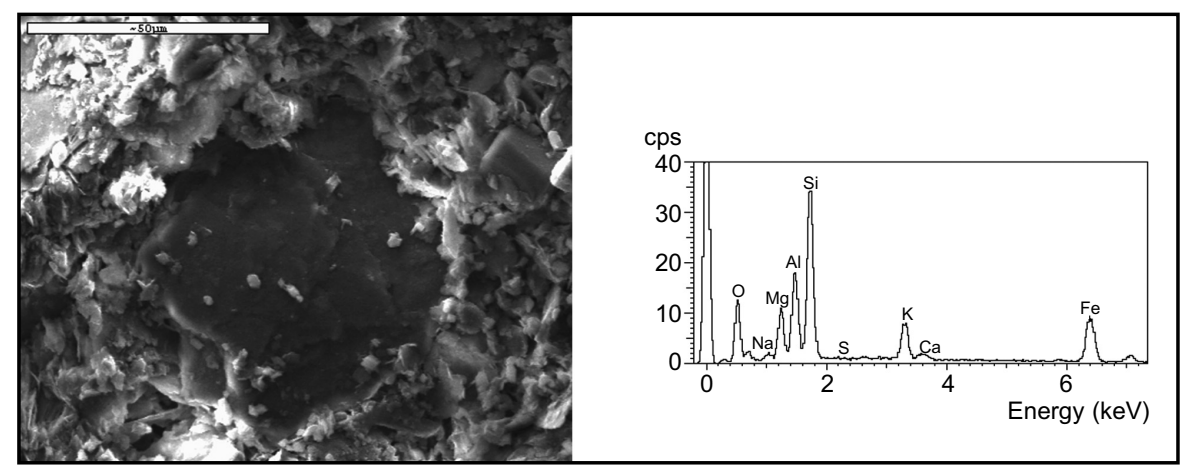

Figuras 17 y 18. Microfotografía de SEM y microanálisis por EDX: presencia de material arcilloso en muestra M.25.

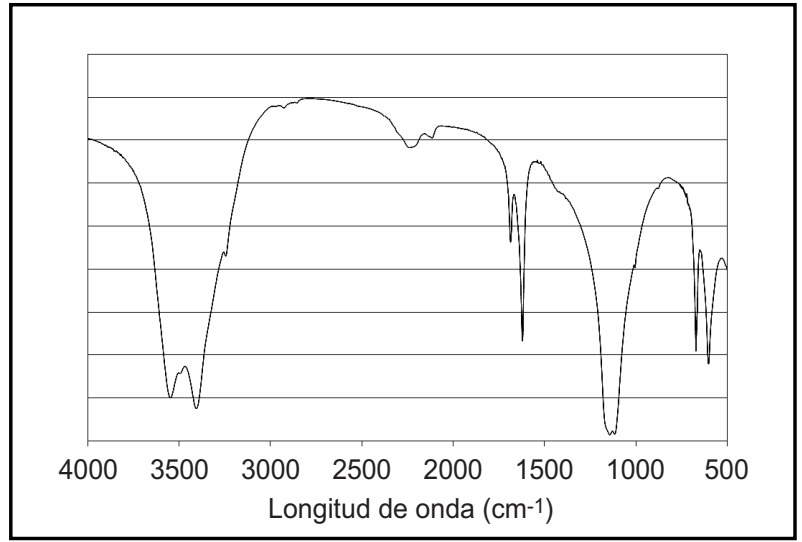

Figura 19. Espectro IR de la capa superficial de la muestra M.1C (extradós). 
semibóveda sur, de posible intervención posterior. A esta diferencia se suma que la madera del camón analizado es de tipo pino de Oregón o Douglas-fir, diferente al Pinus Silvestris de la semibóveda norte. Sin embargo, a pesar de las diferencias cronológicas de las actuaciones, se mantiene la presencia de cerámica machacada en la composición del mortero.

Por otro lado, la existencia de unos materiales orgánicos, madera, tela y fibras vegetales, y de otros altamente higroscópicos, morteros y pastas de yeso, demanda un mantenimiento adecuado, por lo que esta caracterización establece las pautas del mismo y constituye el estudio previo de futuras intervenciones.

\section{AGRADECIMIENTO}

Al arquitecto conservador del Senado don Ignacio Moreno por su colaboración en los trabajos realizados.

\section{BIBLIOGRAFÍA}

(1) Monjo, J.; Bustamante R.: Caracterización y Diagnóstico de molduras, cornisas y techo del Salón de Plenos del Palacio del Senado, Universidad Politécnica de Madrid (Informe enero 2010).

(2) Bustamante, R.; Monjo, J.; Alonso de la Calle, M.: The Modifications of the Main Façade of the Spanish Senate Palace. XXXVII IAHS, Santander, España (2010), p. 334.

(3) Moleón, P.: Isidro Velázquez, Arquitecto del Madrid Fernandino, Madrid (2009).

(4) Ambrós Escanellas, M. (1973): Informe, Archivo del Senado, Madrid.

(5) UNE-EN 998-2 Especificaciones de los morteros para albañilería. Parte 2: Morteros para albañilería.

(6) UNE 102039 Yesos y escayolas de construcción. Determinación de la dureza Shore C y de la dureza Brinell.

(7) Bustamante, R.; Sánchez de Rojas, M. I.: "Estudio de los enlucidos de yeso de la iglesia de San Pedro los Francos de Calatayud", Mater. Construc., vol. 57, no 280 (2007), pp. 53, 64, Madrid.

(8) UNE-EN 15757 Conservación del patrimonio cultural. Especificaciones de temperatura y humedad relativa para limitar los daños mecánicos causados por el clima a los materiales orgánicos higroscópicos.

(9) Sánchez de Rojas, M. I.; Marín, F.; Rivera, J.; Frías, M.: "Morphology and properties in blended cements with ceramic waste materials recycled as pozzolanic addition". Journal of the American Ceramic Society, 89, 12 (2006), pp. 3701-3705.

http://dx.doi.org/10.1111/j.1551-2916.2006.01279.x

(10) Villanueva, L.: Bóvedas de madera, Actas del Cuarto Congreso de Historia de la Construcción, Cádiz (2005), pp. 1105 y 1109. 